Association for Information Systems AIS Electronic Library (AISeL)

Wirtschaftsinformatik Proceedings 2005

Wirtschaftsinformatik

February 2005

\title{
The Emerging WLAN-Infrastructure: Complement or Substitute?
}

Kilian Plank

Johann Wolfgang Goethe University, Frankfurt am Main

Follow this and additional works at: http://aisel.aisnet.org/wi2005

\section{Recommended Citation}

Plank, Kilian, "The Emerging WLAN-Infrastructure: Complement or Substitute?" (2005). Wirtschaftsinformatik Proceedings 2005.84. http://aisel.aisnet.org/wi2005/84

This material is brought to you by the Wirtschaftsinformatik at AIS Electronic Library (AISeL). It has been accepted for inclusion in Wirtschaftsinformatik Proceedings 2005 by an authorized administrator of AIS Electronic Library (AISeL). For more information, please contact elibrary@aisnet.org. 
In: Ferstl, Otto K, u.a. (Hg) 2005. Wirtschaftsinformatik 2005: eEconomy, eGovernment, eSociety; 7. Internationale Tagung Wirtschaftsinformatik 2005. Heidelberg: Physica-Verlag

ISBN: 3-7908-1574-8

(C) Physica-Verlag Heidelberg 2005 


\title{
The Emerging WLAN-Infrastructure: Complement or Substitute?
}

\author{
Kilian Plank \\ Johann Wolfgang Goethe University, Frankfurt am Main
}

\begin{abstract}
For several years a steady accelerating convergence of telecommunications, IT, media, and entertainment (TIME) industries is to be observed. This evolution is more than evident in mobile communications, where, among others, technologies, services, and contents of all four areas are integrated on a mobile device. Besides integration several technologies with different evolutionary roots and original purposes converge regarding their usage scenarios leading to frequently contrasting reciprocal diffusion impacts. This paper analyzes modes of interaction between GSM/UMTS/PSTN and WLAN ranging from substitution to completion. An informal framework will be developed aiming at laying a foundation for further analyses of complex interaction scenarios.
\end{abstract}

Keywords: WLAN, WiFi, GSM, UMTS, Substitute, Complement, Product, Technology, Interaction, Diffusion

\section{Introduction}

For several years an increasingly accelerating convergence of telecommunications, IT, media, and entertainment industries is to be observed. This evolution is more than evident in mobile communications, where technologies, services and contents of all these four areas are integrated on a mobile device. For example, many currently available gadgets are a bundle of mobile telephone, personal computer with internet access, television, radio, video and audio player and recorder, respectively, photo and video camera, game console and finally mobile wallet (including, among others, payment and identification services as well as document archives).

Besides integration of different complementary technologies convergence also entails encounter of different technologies addressing similar customer needs. These technologies have partly different roots and original purposes. For instance, some have been intentionally designed and developed for mobile communications, such as GSM (Global System for Mobile Communications) or UMTS (Universal Mobile Telecommunications System), others were driven evolutionary to a new application scenario and had their roots in IT, such as IEEE 802.11b WLAN (Wire- 
less Local Area Network). WLAN ${ }^{1}$ was originally designed as a means of getting around costly and inflexible LAN (Local Area Network) wired infrastructure installations. However, in the course of time, WLAN evolved in its use cases ${ }^{2}$ and is frequently considered as a substitute to current and growing mobile telecommunication networks like GSM and UMTS. Indeed, there are a lot of yet realized or at least planned urban "WLAN networks", i. e. completely WLAN covered urban areas. In conjunction with VoIP (Voice over Internet Protocol) it shall be possible to use these "WLAN networks" as wireless telephone networks. But many industry experts doubt that these new business models could deliver on their success promises. The recent bankruptcies of several young start-up companies seem to prove them right. Furthermore, it is frequently questioned that a large scale WLAN installation could be a realistic substitute to pure mobile access networks since not being designed for such use cases. Consequently, mobile operators regard WLAN just as a complement to their GSM/UMTS networks at specific public places. This contrasting discussion leads to the question whether WLAN actually is a complement or a substitute.

Literature from several scientific areas has addressed the topic of complement and substitute. There are contributions from marketing which extend the original Bass diffusion model [Bass69] with multiproduct interaction ${ }^{3}$, intergenerational effects (e. g. [KuKu92]) and marketing decision variables (e. g. [Bayu92]). Other marketing and economics works focus on brand-switching behavior among costumers (e. g. [Buck ${ }^{+}$98]), bundling (in terms of optimal bundling, pricing strategies (e. g. [VeKa03]), and consumer behavior (e. g. [Yada94])), customer/market identification (e. g. [DaNe94]) and oligopolistic competition (e. g. [Bulo ${ }^{+} 85$; Klem87]). Strategy and innovation and technology management literature addresses the subject in terms of competitive opportunities and threats (e. g. [Port80; NaBr96]) as well as from the perspective of success and failure, obsolescence as well as attack and defense (e. g. [Chri97; PiUt97; Dann04, p. 254]).

All these approaches and findings just focus partial aspects. Still missing is a comprehensive concept setting terms, factors, relations and dimensions in one common context [Shoc ${ }^{+} 04$, p. 30]. The paper at hand tries to clarify and structure the domain of technology and product interaction. This includes the definition of key terms, the description of relevant dimensions, factors and relations integrated into a generic framework. The interaction between WLAN and UMTS is to serve as a reference case owing to its particularities. First, the technological outcome of this strategically relevant development is not decided yet. Second, it is the first

subsequently short for IEEE (Institute of Electrical and Electronics Engineers) $802.11 \mathrm{~b}$

2 The term "use case" is to be construed here as any kind of (usage) purpose of a product and does not match the popular definition in UML (Unified Modeling Language).

3 Interaction is a generic term for product interrelationships like complementarity or substitution. A precise definition follows later. 
case of widespread distributed private wireless network infrastructures. Third, it is a technology related case which reveals a plethora of phenomena. Fourth, the actual technology does not matter when it comes to building a generic framework. It just matters when it comes to modeling a specific scenario. In that case technological specificities have to be accounted for ${ }^{4}$.

The rest of the paper is organized as follows. First, the GSM, UMTS and WLAN technologies are delineated and compared. In this context, the respective existing and emerging business models will be sketched. In chapter three a selection of competitive relationships among mobile access technologies is presented. By means of a study of the WLAN versus PSTN/GSM/UMTS case the seemingly contradictory nature of technology interaction is demonstrated. Following, the fundamentals for a general framework of technology and product interaction is presented addressing individual, marketing and financial dimensions. Such a framework can serve several purposes. First, it can be used as a means of structuring complex interaction situations by offering dimensions of consideration, factors as well as relations. Second, it can serve as a starting point for product diffusion models and simulation models incorporating product relationships.

\section{Technologies and Business Models}

Following, 2G, 3G and WLAN technologies together with the respective actual and prospective business models are delineated.

\subsection{G and 3G Networks}

$2 \mathrm{G}$ characterizes second generation mobile telecommunications systems differing, among others, in their digital signal transmission from analogue first generation systems. In Europe, all member states agreed on a joint $2 \mathrm{G}$ standard which is called GSM. Apart from digitization, other important novelties were international roaming, messaging and data services. Outside Europe, especially in USA and Japan, further competing standards have evolved.

The most important service categories (from a consumer's perspective ${ }^{5}$ ) available with GSM and its successors are voice communication, messaging (e. g. SMS, MMS) ${ }^{6}$, internet access, content, and services. Especially the last three service categories require high and still growing bandwidth (e. g. for mobile television,

Section 3 mentions several other future technologies and corresponding interactions.

GSM itself discerns technical service categories [TuPo04, p. 12].

SMS: Short Message Service, MMS: Multimedia Message Service 
video download or mobile video telephony, etc.). However, GSM only provides insufficiently low data rates of $9.6 \mathrm{kbit} / \mathrm{s}$ [TuPo04, p. 32].

In view of this deficiency and because of international standards heterogeneity (e. g. hampering roaming), a new worldwide broadband mobile telecommunications standard framework (called IMT-2000) for third generation mobile telecommunications (3G) was developed [TuPo04, p. 12]. The European Union member states again agreed on a specific standard within this framework called UMTS. Since UMTS implies high investments in terms of both license fees and infrastructure upgrades and because of general economic considerations most mobile network operators decided for a gradual transition to 3G. Such gradual transition stages are GPRS and EDGE, two standards increasing data transmission rates from $9.6 \mathrm{kbit} / \mathrm{s}$ to $56 \mathrm{kbit} / \mathrm{s}$ and $384 \mathrm{kbit} / \mathrm{s}$, respectively [Schi03, p. $161 \&$ p. 177; TuPo04, p. 12, 40].

Since GSM and UMTS show a top-down, centralized deployment and service provision approach [LeMc03, p. 18] and imply high investments and regulatory obligations [LeMc03, p. 359] there are few opportunities for new entrants into the operator business. However, besides network operating there are other promising and yet successful business models, such as application, content and service development, aggregation and operation, equipment and device production and contract reselling [TuPo04, pp. 130].

\subsection{WLAN 802.11b/WiFi ${ }^{7}$}

IEEE $802.11 \mathrm{~b}$ WLAN was originally designed to get around costly and inflexible wired LAN infrastructures. WiFi works in non-licensed spectrum and allows data rates of up to $11 \mathrm{mbit} / \mathrm{s}$. Since its advent, WLAN access points and routers have become popular home network commodities. This may, among others, be due to both large price declines and bundle offers of broadband internet access providers linking WLAN equipment with service contracts. Apart from the growing diffusion of private "hot spots" WiFi was also recognized as a business opportunity, especially at public places like stations, hotels, restaurants, etc. WLAN is to provide internet access there for people lacking high-bandwidth connections outside the office or home. Furthermore, new concepts try to deploy WLAN as a substitute for incumbent mobile communications networks. In these scenarios, large areas, like cities, are completely covered with WLAN. With WiFi-enabled handsets in conjunction with higher-level protocols like VoIP even telephone calls could be made from everywhere in this 'WLAN-network' ${ }^{8}$. Indeed, many major handset manufacturers announced to offer WLAN-enabled gadgets soon with some al-

\footnotetext{
7 WiFi stands for "Wireless Fidelity" and is an industry consortium's label for IEEE $802.11 \mathrm{~b}$.

8 Notice that "WLAN-network" means a network of networks.
} 
ready delivering first models. The major benefits of WLAN are a high maximum data rate as well as low seeming deployment costs in relation to GSM or UMTS installations.

Figure 1 summarizes the main business opportunities for WLAN infrastructures currently under discussion.

\begin{tabular}{|c|c|}
\hline \multicolumn{2}{|c|}{ Part of Marketing Mix } \\
\hline Channel & Customer Relationship Management \\
\hline Business Model \\
\hline Petwork Access & Aggregator / Intermediary \\
\hline Pdditional access mode to existing networks \\
\hline
\end{tabular}

Figure 1: WLAN employment in a business context ${ }^{9}$

Generally, there are three categories of business scenarios for WLAN. First, WLAN is used as a part of the overall marketing-mix, such as yet another channel for customer communication and distribution. Furthermore, it can be employed as a means of customer relationship and customer retention, respectively. For example, WLAN can be provided as a free add-on for the customer at the point of purchase. A more sophisticated example would be bundling primary products (e. g. meals, coffee) with WLAN so that WLAN-usage is bonded to the purchase of other products. If the customer attaches a higher value to the combination of both products, he will either buy more or pay more.

The second class of business models embodies the above mentioned WLAN operator scenario. Here, the operator charges fees for network access. The operator does not have to have any special skills regarding telecommunications or IT. He only needs a high-bandwidth internet connection and the necessary WLAN equipment. Of course, this kind of model does not allow for mobility and possibly imposes separate registration and billing procedures with each hot spot operator on the user. This implies negative indirect network effects for the customer. Therefore, unification of registration and login would be beneficial. This is the role of the aggregator in the network. The aggregator operates a central database with static and dynamic user information and thus provides for registration, identification, and billing. The aggregator could also act as a central point for handover and roaming among hot spots and therefore occupies the role of a clearing house [TuPo04, p. 51]. Thus, a major drawback compared with GSM/UMTS networks

9 Focusing on business models for the operator of the WLAN and disregarding other value net roles like content and application developers or equipment manufacturers because of their being largely independent of the access network. 
would be resolved $^{10}$. The aggregator compensates for the problems of a decentralized, bottom up and heterogeneously owned infrastructure.

The third class of business models employs WLAN as an alternative access technology. A first example is GSM operators trying to integrate WLAN into their set of other access technologies. Their strategy expects the customer to use the most appropriate technology according to their context. Another example is PSTN (Public Switched Telephone Network ${ }^{11}$ ) operators trying to redirect mobile communications traffic into their networks. This is achieved by handsets that automatically connect to a local access point rather than to the cellular network when the user is at home.

\subsection{G/3G - WLAN Comparison}

A couple of differences between WLAN and GSM/UMTS have already been mentioned, such as different network architecture and ownership, different original purposes, the difference between mobility and wireless and finally spectrum regulation. Especially the last aspect has a number of implications. Firstly, as opposed to GSM/UMTS spectrum WLAN works in the freely available ISM (Industrial, Scientific and Medical) band. GSM/UMTS operators often are charged enormous fees for a license from regulatory oversight. But having an exclusive frequency band protects largely from interference leading to higher service quality. On the other hand, holding a license in many countries implies particular duties regarding operating, infrastructure, building schedules, and offered services. Operating in the free ISM band does not impose any of these obligations. Altogether, building traditional mobile infrastructures implies extraordinary high upfront costs ${ }^{12}$ making market entries very difficult. Despite its apparently relatively low upfront investments a comparison between WLAN and GSM/UMTS in terms of overall costs is very difficult.

Additionally to the drawbacks of a shared medium and the lack of mobility WLANs only have a maximum range of 300 meters whereas GSM/UMTS cells can span a maximum of 30 kilometers [TuPo04, p. 15, 49]. However, all these values depend on environmental factors, e. g. user density, buildings, natural factors, and therefore are difficult to compare.

As stated earlier, another major difference between both models is the decentralized approach of WLAN compared to the centralized approach of GSM/UMTS. In order to realize a scenario in which customers share their private hot spots with others and customers trust such decentralized networks for their private communi-

10 As suggested earlier, WLAN was designed for wireless use cases instead of mobility.

11 PSTN operators own and operate a landline network including the local loop to the end customer.

12 There were particularly large differences among countries regarding license fees. 
cations requires an attractive incentive system as well as elaborate security and privacy mechanisms.

Given all the differences a uniform concluding assessment is not possible. Still, in view of so many new wireless standards emerging from the IT industry (e.g. $802.11 \mathrm{~g}, 802.11 \mathrm{a}, \mathrm{WiMax}^{13}$ ) the evolution of decentralized technologies appears more dynamic and perhaps more flexible and adaptable as to upcoming problems.

\section{Technology Interactions}

\subsection{Competitive Interactions in the Telecommunications Industry}

At first sight, the operator model discussed in section 2 shows WLAN as a clear substitute for GSM as well as UMTS, since both compete for customers in the same use cases. However, remembering the aforementioned integration strategy of incumbent mobile operators renders a contrasting picture. There, WLAN is a complementary technology besides GSM and UMTS. Therefore, the question arises what the real nature of this technology interaction is, i. e. whether it is a substitute or a complement.

The relevance of this question is grounded in the significant influence of technology and product interactions on a technology's or product's diffusion and overall success, respectively. This is all the more essential for the telecommunications industry which faces extremely high innovation rates and short product lifetimes. As suggested earlier, convergence towards a common TIME industry and high innovation rates in wireless IT standards, among others, foster the evolution of many seemingly competing and complementary technologies. Figure 2 gives a survey of current and possible future substitution relationships among various existing and new technologies. The illustration differentiates between the degree of novelty ${ }^{14}$ as well as the origin ${ }^{15}$ of the competing technologies.

13 WiMax is an industry consortium aiming at supporting the development and adoption of IEEE 802.16 standards for metropolitan area network technologies.

14 New and prospective technologies versus established technologies

15 Telecommunications in contrast to non-telecommunications roots 


\begin{tabular}{|c|c|c|}
\hline Generation & Telecommunications industry & TIME industries \\
\hline $\begin{array}{l}\text { existing } \\
\text { vs. } \\
\text { existing }\end{array}$ & $\begin{array}{l}\text { - GSM vs. PSTN/ISDN } \\
\text { - GSM vs. DECT } \\
\text { - PSTN vs. ISDN } \\
\text { - Industrial Radio vs. P2T }\end{array}$ & no convergence yet \\
\hline $\begin{array}{l}\text { existing } \\
\text { vs. } \\
\text { new }\end{array}$ & $\begin{array}{l}\text { - GSM vs. UMTS } \\
\text { - GPRS vs. UMTS } \\
\text { - PSTN/ISDN/DECT vs. UMTS } \\
\text { - GSM vs. DSL }\end{array}$ & $\begin{array}{l}\text { - GSM/GPRS vs. WLAN } \\
\text { - Cable-Broadcasting vs. WLAN/DSL/ } \\
\text { UMTS/WiMax } \\
\text { - PSTN/ISDN vs. VoIP } \\
\text { - DVB-H/T vs. WLAN/DSL/UMTS }\end{array}$ \\
\hline $\begin{array}{l}\text { new } \\
\text { vs. } \\
\text { new }\end{array}$ & $\begin{array}{l}\text { - EDGE vs. UMTS } \\
\text { - WCDMA (UMTS) vs. CDMA2000 }\end{array}$ & $\begin{array}{l}\text { - WLAN }{ }_{(802.11 x)} \text { vs. UMTS } \\
\text { - WiMax vs. UMTS } \\
\text { - UMTS vs. DSL }\end{array}$ \\
\hline
\end{tabular}

Figure 2: Substitution interactions in telecommunications and converging TIME industries ${ }^{16}$

Without considering the various interaction relations in detail their multitude is evident. However, neither does figure 2 state anything about the degree of competition nor does it describe the nature of the influence between two technologies. Moreover, considering each technology-pair in more detail also reveals complementary aspects. Following, this phenomenon will be studied in more detail by the case of PSTN/GSM/UMTS versus WLAN.

\subsection{Interactions between PSTN/GSM/UMTS and WLAN}

In this section, the analysis is restricted to four technologies owing to their high industry relevance. Figure 3 summarizes substitution as well as complementary aspects of WLAN deployment towards PSTN, GSM and UMTS.

16 This illustration does not claim comprehensiveness; furthermore, a clear definition of "existing" and "new" is missing. 


\begin{tabular}{|c|c|c|c|}
\hline & PSTN & GSM & UMTS \\
\hline \multirow[t]{2}{*}{ Complement } & $\begin{array}{l}\text { alternative access } \\
\text { technology to own core } \\
\text { network (Appropriability) }\end{array}$ & \multirow{2}{*}{$\begin{array}{l}\text { alternative wireless access } \\
\text { technology to own core } \\
\text { network at places poorly } \\
\text { covered by GSM } \\
\text { (Appropriability) }\end{array}$} & \multirow{2}{*}{$\begin{array}{l}\text { alternative wireless access } \\
\text { technology to own core } \\
\text { network at places poorly } \\
\text { covered by UMTS } \\
\text { (Appropriability) }\end{array}$} \\
\hline & $\begin{array}{l}\text { means of redirecting mobile } \\
\text { telecommunications traffic } \\
\text { to own core network }\end{array}$ & & \\
\hline \multirow[t]{2}{*}{ Substitute } & \multirow[t]{2}{*}{$\begin{array}{l}\text { carrier technology for } \\
\text { substitute services, e.g. } \\
\text { VoIP. }\end{array}$} & $\begin{array}{l}\text { carrier technology for } \\
\text { substitute services, e.g. } \\
\text { VoIP. }\end{array}$ & $\begin{array}{l}\text { carrier technology for } \\
\text { substitute services, e.g. } \\
\text { VoIP. }\end{array}$ \\
\hline & & $\begin{array}{l}\text { alternative broadband } \\
\text { wireless access technology } \\
\text { to external backbone } \\
\text { networks (Non- } \\
\text { Appropriability) }\end{array}$ & $\begin{array}{l}\text { alternative broadband } \\
\text { wireless access technology } \\
\text { to external backbone } \\
\text { networks (Non- } \\
\text { Appropriability) }\end{array}$ \\
\hline
\end{tabular}

Figure 3: WLAN as complement and substitute to PSTN, GSM, and UMTS

Broadly speaking, when WLAN serves as an alternative access technology to the operator's own core network, that is, when the data traffic flows over his own networks, WLAN has a supplementary character. Especially at places at which high data rates are necessary and little GSM or UMTS coverage is available WLAN is a good supplement for GSM and UMTS networks. With PSTN operators WLAN can serve as an alternative to wired telephone devices and DECT (Digital Enhanced Cordless Telecommunications System) systems. This has nearly no effect on the operator's revenues. Furthermore, it can be exploited as a means to redirect mobile communications traffic into PSTN networks ${ }^{17}$. For this purpose, dual handsets are necessary which can operate in both GSM/UMTS and WLAN networks. Of course, in this case, WLAN is a substitute for GSM and UMTS operators since revenues flow to another operator. Generally, whenever WLAN is connected to a different backbone network WLAN revenues are not appropriable for the focal firm, i. e. revenues flow to a different operator. But there is even a case in which despite appropriation revenues can be reduced by WLAN. This happens when WLAN is only a carrier technology, that is, an enabler for a substitute technology. An example for that is VoIP, an IP based voice communications technology strongly linked to WLAN. VoIP packs up digitized voice into data (IP) packages. Hence, even though the IP traffic is routed over the operator's own core network the difference between charges for voice transmissions and data transmissions causes a decline in revenues since the former are usually higher than the latter.

The analysis up to now has offered some insight into the complex nature of technology interactions. In order to structure these findings more precisely, following, a more general analysis shall be given which is to serve as a basis for a later overall framework for technology interactions.

17 British Telecom (BT) and Korean Telecom (TK) recently announced their intention to offer such converged mobile - fixed-line service. 


\section{Interaction Framework}

Figure 4 depicts the building blocks of the framework which will be presented subsequently, however, owing to interdependencies among the blocks partly in a different order.

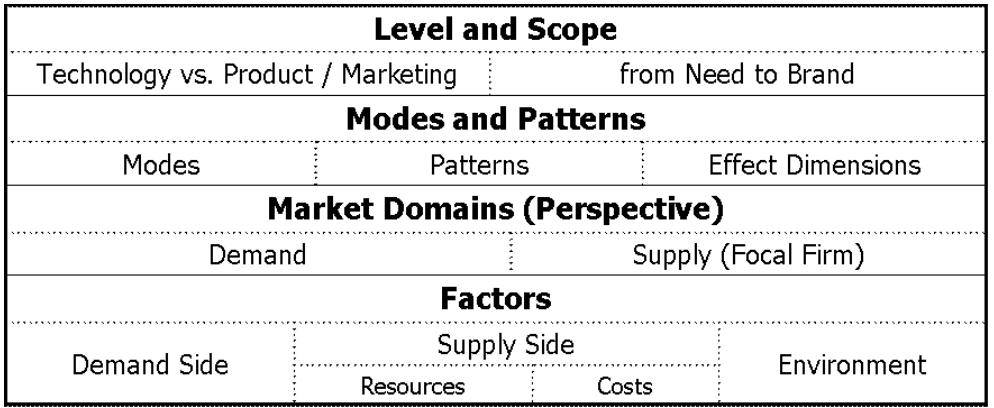

Figure 4: Building blocks of the interaction framework

\subsection{Basic Modes and Patterns of Interaction}

Figure 5 gives a survey of four archetypes of product relations following [MaPe85, pp. 39]. A contingent product strongly depends on another product, and thus, is generally adopted in conjunction with the other one. Independent products, on the other hand, do not influence each other, at least within a certain problem scope (cf. section 4.2). However, there is always at least the common constraint of consumer budget which represents the widest possible scope.

\begin{tabular}{|c|c|c|c|}
\hline \multicolumn{3}{|c|}{ Product and Technology Relations } \\
\hdashline Contingency & Independence & Complement & Substitute \\
\hline
\end{tabular}

Figure 5: Basic modes of technology interactions

If both products influence each other positively ${ }^{18}$ in terms of adoption, they are called 'complements'. On the other hand, if both products influence each other negatively, they are called 'substitutes' [ $\operatorname{Shoc}^{+} 04$, p. 29]. Besides, there are cases in between these extremes in which one product fosters the other and the other hampers the first or in which there is just unilateral influence. There may be even the case of positive influence by a technological substitute when the emergence of a new technology triggers improvements in the mature technology. All this sug-

18 A possible measure is the growth rate change [PiUt97, p. 71]. 
gests that modes of technological interaction and initial superiority need not reflect on the later market one-to-one, since reactions of the "other product" cannot be ruled out. This difference between the technology and its later appearance on the market, as a product, will be discussed later in this section.

$\left[\mathrm{Bayu}^{+} 00\right.$, p. 155] developed a conceptual framework for multiproduct ${ }^{19}$ interaction showing the various possible positive, negative, and neutral mutual effects of existing and new products and arranging them in different categories. [Shoc $\left.{ }^{+} 04\right]$ extend the conventional static model with dynamic aspects allowing for order of entry, such as intergenerational effects. More precisely, the nature of an interaction between two technologies or products is likely not static but may change in the course of time [Shoc ${ }^{+} 04$, pp. 33]. For example, several years ago, mobile telephony was an additional service to the former fixed line communication. But in the course of time, driven by price decline, domestication, technological improvements, and diffusion effects a growing part of fixed line calls has been being replaced by mobile calls. Former complements ultimately became substitutes ${ }^{20}$ [Shoc ${ }^{+}$04, pp. 35]. As will be illustrated in section 4.4.1 there is also the case that the consumer himself develops or fosters new usage scenarios which have been disregarded by marketing thus far. A case in point is SMS which has not been considered as a relevant product at the beginning. But with its unexpected rapid diffusion, a wealth of new SMS based services emerged. The dynamic character becomes particularly obvious with respect to feedback processes, caused, for instance, by standardization and network effects. Apart from consumer induced changes, the competitor's reactions as well as environmental shifts may also account for interaction dynamics.

However, although the aforementioned "pattern" frameworks are suitable for product diffusion models they disregard a lot of aspects, such as technology, strategy, or financials. The following sections will address these issues, among others.

\subsection{Different Levels and Scope}

Because of their undifferentiated use in this paper up to now the terms "product" and "technology" are to be specified. Literature construes technology as applied scientific knowledge for the resolution of specific problems [Pohl96, p. 19]. On the other hand, a product is a material and/or immaterial aggregate of perceived qualities linked with utility expectations (cf. e. g. [Kot191, pp. 429]). Therefore, users generally do not perceive technologies in the first place but rather products. Of course, technologies do influence a product's qualities. Moreover, one technol-

19 Interactions among more than two products simultaneously are to be examined pairwise and consequently are not treated separately [Shoc ${ }^{+} 04$, p. 28].

20 [Shoc ${ }^{+} 04$, pp. 35] calls this phenomenon 'reincarnation'. 
ogy can realize various products and in one product several technologies can be employed.

Furthermore, interaction also depends on the regarded scope. In order for a specific need to be satisfied many product categories may be appropriate and within these categories there may be several subcategories or brands which possibly act as substitutes [Kot191, p. 133]. For instance, the need for communication may be satisfied by mail, meeting, telecommunications, etc. Telecommunications, in turn, offers voice telephony or messaging. Messaging, in turn, comprises substitutes like e-mail, SMS, or MMS which in turn are offered by different suppliers (implying different brands). The notion of a "product hierarchy" expresses the issue of product dependencies at various scope levels [Kot191, p. 431].

\subsection{Demand Side}

What do these specifications mean in the context of consumer perception? (1) Suppliers focus on technologies as well as on products while consumers just perceive products. (2) If a consumer perceives two products as mainly identical, he is indifferent in terms of the underlying technologies. This is a consequence of the above definitions. So, if two technologies' different qualities do not reach the consumer's perception, competition emerges at the product and marketing level, respectively, otherwise, competition also takes place at the technology level. If WLAN, for example, offered the same service quality (coverage, roaming, handover, voice quality, security) as GSM/UMTS, people will most probably base their purchase and usage decisions on marketing traits like price. Otherwise, they will look at technological product qualities, i. e. product qualities mediated by the underlying technology.

Of course, apart from technology and product qualities, individual characteristics as well as the purpose of a purchase or a usage are key further determinants of whether a product is considered as complement or substitute [Shoc ${ }^{+} 04$, p. 30, 31]. As an example for purpose take SMS and MMS. While in normal life SMS and MMS may be considered substitutes (even if most people currently still prefer SMS), MMS could become a complement when travel photos shall be communicated immediately. In one case both products are substitutes since they serve the same purpose (i. e. use case), in the other case they serve different purposes and therefore do not compete but rather supplement one another. This suggests that interaction has to be defined in terms of purposes or use cases since one product can be appropriate for several purposes [ $\operatorname{Ratn}^{+} 99$, pp. 193; Kot191, p. 133]. Below, this point will be elaborated.

[Poh196] examined the adoption decision of technological innovations and determined a deviation from the usual decision process. Owing to difficulties in assessing the new technology, its utility and future and also because of highly dynamic markets the consumer suffers high purchase uncertainty. This may lead to cancel- 
lation or postponement of the purchase process. TIME markets show that kind of dynamics. Because of uncertainty and announcements of promising substitutes consumers could skip the current generation and only adopt the next one ${ }^{21}$. This leads to so called intergenerational interaction effects. In this case, the existing generation is negatively influenced by the future generation.

\subsection{Supply Side}

With disintegrating value chains relationships between value network actors become increasingly complex and each party may be affected in a different way by interaction. For example, the competition character in the relationship of WLAN and UMTS may affect equipment manufacturers as well as operators but does not affect content providers at all. Thus, in the following, the relevant interaction aspects for a generic supply side actor are presented. They have to be applied to each actor in a real setting separately.

\subsubsection{Marketing}

\subsubsection{Relationship between Marketing, Technology and User Needs}

As suggested above, users perceive products and products again are created by marketing ${ }^{22}$. In Figure 6 this point is made clear. Needs and problems are drivers of consumption. Technology has been defined as scientific knowledge aiming at the resolution of certain problems (cf. section 4.2). Therefore, technology determines the set of theoretically possible use cases ${ }^{23}$. However, many of these use cases are irrelevant, ineffective or inefficient, or even not (yet) identified and therefore are never (not yet) offered.

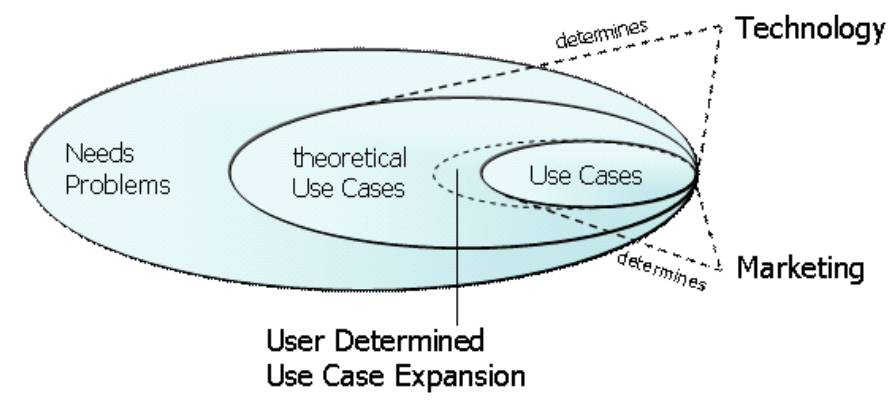

Figure 6: Context of technology, marketing, and use cases

\footnotetext{
21 This behaviour is called "leapfrogging" [Poh196].

22 This logic follows from the definition in section 4.2.

23 In their framework [Ratn $\left.{ }^{+} 99\right]$ denote this "purposes"
} 
It is one of the tasks of marketing to select suitable and appropriate ${ }^{24}$ use cases from the set of possible use cases and transform them into products. Marketing has to position a product on a market. A product market can be defined as a set of products considered (among consumers) appropriate for serving a particular purpose or resolving a particular problem, respectively. Thus, substitutability among products, serving the same purpose (i. e. use case), constitutes a market [Ratn ${ }^{+} 99$, p. 201]. This holds irrespective of whether interaction occurs at the technology or at the product level.

Figure 6 also includes the possibility of evolution. It is sometimes the case that consumers invent new use cases into the set of theoretical use cases, which have not been identified from marketing yet. This "freedom" seems rather confined with proprietary, top-down structured and standardized mobile operator networks. However, taking the success of SMS, which has initially been ignored of being a reasonable use case, shows an example of user driven use case determination. Another example is WLAN which has not been considered for what it is currently being used.

Figure 7 illustrates the case of technology interaction. There are two technologies which have common theoretical use cases (i. e. their theoretical use case sets overlap). Some of the addressed use cases of the alternative technology 2 intersect the set of addressed use cases of technology 1 (i. e. use cases which are chosen by marketing $)^{25}$. In this purple colored area, interaction actually takes places.

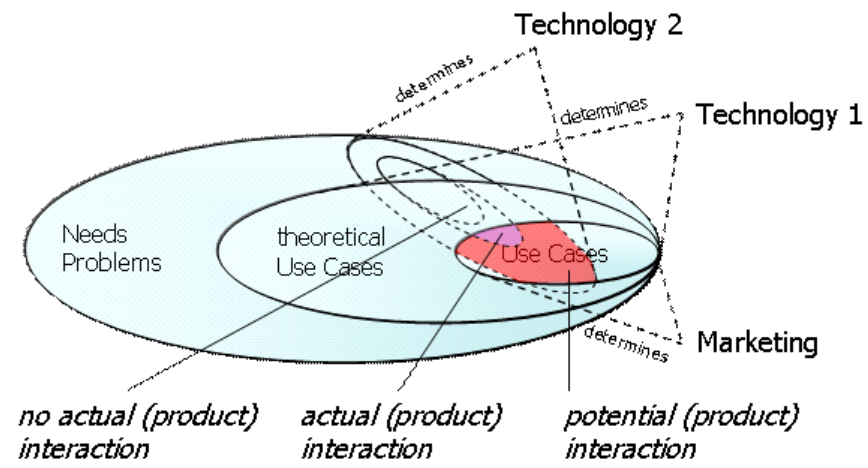

Figure 7: Intersection of theoretical use case sets of two technologies

Figure 7 can be applied to the case of WLAN and GSM/UMTS. In the beginning, WLAN and GSM had completely different theoretical use cases. WLAN aimed at wireless access to a data network whereas GSM aimed at mobile telephony. Both theoretical use case sets had hardly any intersects. In the course of time, GSM de-

\footnotetext{
24 i. e. appropriate according to the supplier's targets

$25 \quad\left[\mathrm{Kim}^{+} 00\right.$, pp. 496; Shoc ${ }^{+} 04$, p. 28] call this "intercategory" interaction.
} 
veloped higher data rates and WLAN evolved as an alternative to DECT. Both have approached each other and, thus, the intersection has expanded. Now that UMTS is emerging the intersection is comparatively large. UMTS addresses high data rates and WLAN gradually offers first approaches of mobility (by growing coverage and handover mechanisms). Currently, most European mobile network operators try to integrate WLAN by assigning it to specific use cases, e. g. public locations with high data rate requirements, in which UMTS is not the best fit (for this use case) anyhow. Doing this means reducing the (addressed) use case set within technology 1 (GSM/UMTS) and opening a new set of (addressed) use cases within technology 2 (WLAN).

\subsubsection{Strategic Marketing}

The question of whether to integrate an interacting technology or not is part of the product policy. Integrating substitute technologies holds the danger of cannibalization. Not integrating a substitute technology holds the danger of customer churn. Integrating a complementary technology may lead to higher profits but does not exclude overall losses. Finally, not integrating a complement includes the risk of customer churn, especially if product bundles are highly demanded. Later in the next section this discussion will be picked up again.

Besides integration a company can chose among several other strategic moves when facing a substitution threat [Shoc ${ }^{+} 04$, p. 34]. Firstly, the firm can develop new products or improve existing ones in order to offset or exceed the "competitor's' utility. This requires careful coordination of marketing and research and development activities (R\&D). Apart from the development of new products improvement in manufacture processes could lead to lower costs which in turn could be passed to the customer. Irrespective of the achievement of lower costs price cuts are always a general means of marketing of influencing 'net utility'. Of course, other marketing instruments, such as advertising, branding, distribution, or service, can also change the consumer's perception. Finally, according to the above concept of use case selection product repositioning offers a possibility of avoiding competition. However, this could imply a loss of profits.

\subsubsection{Effect Dimensions of Interaction}

Generally, interaction may precipitate in a company's economic results (see figure 8 ) in two ways: revenues and costs (and consequently profits).

\begin{tabular}{|c|ccc|}
\hline \multicolumn{3}{|c|}{ Effect Dimensions of Interaction } \\
\hdashline Revenue & & Cost \\
\hline Adoption & Usage & Market Potential & \\
\hline
\end{tabular}

Figure 8: Tangible market implications of interaction 
The interaction of two products can either increase or decrease the diffusion rate (i. e. the number of new adopters at a point in time) of one or both of the products. It can further influence the actual usage of one or both of the products and also the market potential (e. g. since the complement expands the primary product's possible use cases). Finally, interaction may affect costs directly or indirectly (e. g. less production costs, economies of scale). However, owing to complexity there are no general rules or categorizations for the extent and sign of all these effects.

For example, in case an integrated technology substitute draws a lot of demand from the primary product (which is based on a different technology) it depends on the margins of the substitute whether overall profits rise or fall. This negative effect of own products on own products is called "cannibalization" and often may result from unsuccessful product positioning. On the other hand, non-integration of technology substitutes can lead to customer churn and dropping revenues and profits. A growing penetration of the substitute in turn could imply feedback effects ${ }^{26}$ reinforcing the substitute's diffusion and further losses in sales and profits for the focal company.

Even the integration of a technology complement can affect profits negatively. For example, if an integrated complementary technology indeed fosters the demand for the primary product but itself generates losses. However, integrating a complement offers chances for higher revenues and profits. For instance, mobile handsets with built-in camera are considered as a complement from mobile network operators (as fostering usage of data transmission products) as well as from handset manufacturers (as fostering handset sales owing to the bundle's higher utility to many consumers) since both expect higher profits from this combination. The handset manufacturer builds a bundle between handset and camera whereas the operator just utilizes the complementary relationship.

\subsection{Factors}

Figure 4 in this section also includes the building block "factors". Factors are causes which affect the strength of interaction. Concerning the demand side the most important factor for substitutability seems to be the degree of perceived problem-solving (or need-satisfaction) congruence of products, i. e. the higher the congruence perceived the higher substitutability. Moreover, if the consumer is already invested, the substitute power of another product depends on his switching costs, like network effects, depreciations, uncertainties, etc. The supply side may influence the degree of substitutability by means of their market positioning decision. Whether a substitute relation really emerges at all depends on a company's

\footnotetext{
26 e. g. economies of scale, network effects
} 
competitors ${ }^{27}$. Hence, it is a matter of raising or lowering market entry barriers or more generally "market structure rigidities". Market structure rigidities are to be construed as factors which keep the market structure from changing. The major categories are: demand side rigidities (e. g. consumer switching costs), resource based rigidities (e. g. scarce resources like spectrum, capital) as well as production cost rigidities (e. g. economies of scale, learning effects). Resource based rigidities offer an example of an environmental factor (cf. figure 4). For instance, regulatory policy often limits the amount of spectrum licenses and thus, the amount of substitutes.

Complementary relations, on the other hand, are characterized by net utility gain $^{28}$ from joint purchase, consumption or usage of different products. Product bundles, for instance, are marketing based complementarities and need not necessarily be technological complements either. Here, price, positioning, channel, and other marketing measures are decisive factors. Technology based complementarity is characterized by compatibility. The relation's strength relies on the attractiveness of the complementary product. The more attractive the complement the higher the attractiveness of the primary product. Hence, in addition, the larger the amount of complementary products for a focal product the larger the potential usage scenarios and, thus in turn, the higher the attractiveness of the focal product ${ }^{29}$. This is often referred to as network effects or increasing returns from variety of complementary products. This way, a firm may influence interaction by its compatibility decision as well as by fostering complementary products.

The treatise on factors has to be finished here. More elaboration requires a separate article.

\section{Conclusion}

This paper tried a first step toward clarifying the difference between technology and product interaction. Irrespective of the kind of interaction at the technology level the mode at the product or market level may be completely different owing to consumers' perceptions, competitors' reactions as well as environmental conditions. The empirical object was the mobile telecommunications industry owing to its high innovation rates, its short product lifetimes, its system good character as well as the convergence phenomena. By means of the case WLAN versus GSM/UMTS the diverse and contrasting reciprocal influences were sketched.

27 It is assumed that a firm does not offer substitutes within their own product line. Product differentiation does not fall into the substitute category.

28 I. e. utility exceeds price.

29 These are logically deduced propositions. 
However, as figure 2 shows, there are a lot of other existing or future interaction cases.

The difficulty of giving a clear answer to the question of whether WLAN be a substitute or a complement leads to the development of a rough framework embodying the most relevant dimensions. First, the different modes of interaction and the contrast between technology and product were delineated. Then, based on this, the demand side and the supply side were examined separately. The key aspects of consumer's assessment of interaction are the consumer's perception of products (instead of technologies) as well as the consumers' heterogeneity. This led to the conclusion that when two technologies address the same customer needs or problems the customer is indifferent in terms of technologies. An aspect which may be reflecting in the current attempt of mobile network operators to rename UMTS (a rather technical term) in terms more stressing need fulfillment. On the part of the suppliers, the framework distinguished marketing, including marketing strategy, and profit implication. Marketing, in connection with research and product development, is responsible for controlling interactions (e. g. by means of price, channel, use case, and positioning). One of the most important decisions is how to react to an emerging interaction, whether to integrate or not. This strategy may have high impact on the firm's economic figures. The multitude of possible outcomes of different interaction scenarios is analyzed in a section on economic impact. Finally, a short section on factors sketches the relevant aspects of interaction strength.

Considering the topic of technology interaction, it goes without saying that this paper was just a first approach, a first attempt to structure this multidimensional domain. Still, it is to lay the conceptual building blocks for models of such complex settings. Future research may go in different directions.

First, more empirical evidence is necessary to assess the actual extent of specific interactions, to find indicators, and to test the propositions' validity. These findings are necessary for the selection and adjustment of parameters in simulation, growth and forecasting models, respectively. There are already several contributions from marketing literature regarding diffusion models allowing for multiproduct or intergenerational interaction $\left[\mathrm{Shoc}^{+}\right.$04; $\mathrm{Bayu}^{+} 00$; PeMa78] ${ }^{30}$. However, these kinds of models often do not cope with the high complexity of system goods and thus give just partial accounts $\left[\mathrm{Bayu}^{+} 00\right.$, p. 160]). Simulation approaches (based e. g. on System Dynamics or on agent models) seem very promising here ${ }^{31}$ owing to their mapping of causal relations. Further research in this direction requires the elaboration of factors (cf. section 4.5) like strategic moves and market structure at the supply side (e. g. product policy, positioning, vertical integration and price) or consumer behavior and switching costs at the demand side.

30 See for example [Bayu ${ }^{+} 00$, pp. 144] for a good survey.

31 See for example $\left[\mathrm{BeBe}^{+} 03\right]$ and [Loeb96]. 


\section{Acknowledgement}

The author thankfully acknowledges the financial support from Deutsche Telekom Stiftung which is funding this Ph.D. research project.

\section{References}

[Bass69] Bass, F.M.: A new product growth model for consumer durables. In: Management Science, 1969, 15, pp. 215-227.

[Bayu92] Bayus, B.L.: The Dynamic Pricing of Next Generation Consumer Durables. In: Management Science, 1992, 11, pp. 251-265.

[Bayu $\left.{ }^{+} 00\right]$ Bayus, B.L.; Kim, N.; Shocker, A.D.: Growth Models for Multiproduct Interactions: Current Status and New Directions. In: Mahajan, V.; Muller, E.; Wind, Y. ed., New-Product Diffusion Models. Kluwer Academic Publishers: Norwell, 2000, pp. 141163.

[BeBe ${ }^{+}$03] Beck, R.; Beimborn, D.; Weitzel, T.: The German Mobile Standards Battle. In: Proceedings of the Hawaii International Conference on System Sciences, January 2003.

[Buck ${ }^{+}$98] Bucklin, R.E.; Russel, G.J.; Srinivasan, V.: A Relationship Between Price Elasticities and Brand-Switching Probabilities. In: Journal of Marketing Research, 1998, 35, pp. 99-113.

[Bulo $\left.{ }^{+} 85\right]$ Bulow, J.I.; Geanakoplos, J.D.; Klemperer, P.D.: Multimarket Oligopoly: Strategic Substitutes and Complements. In: Journal of Political Economy, 1985, Vol. 93, no. 3, pp. 488-511.

[Chri97] Christensen, C.M.: The Innovator's Dilemma: When Technologies Cause Great Firms to Fail. Havard Business School Press: Boston, 1997.

[DaNe94] Day, G.S.; Nedungadi, P.: Managerial Representations of Competitive Advantage. In: Journal of Marketing, 1994, Vol. 58, pp. 31-44.

[Dann04] Danneels, E.: Disruptive Technology Revisited - A Critique and Research Agenda. In: The Journal of Product Innovation Management, 2004, Vol. 21, pp. 246258.

[Klem87] Klemperer, P.: The competitiveness of markets with switching costs. In: Rand Journal of Economics, 1987, Vol. 18, no. 1, pp. 138-150.

[Kot191] Kotler, P.: Marketing Management. Prentice-Hall: Englewood Cliffs, 1991.

[KuKu92] Kumar, U.; Kumar, V.: Technological Innovation Diffusion: The Proliferation of Substitution models and Easing the User's Dilemma. In: IEEE Transactions on Engineering Management, 39, 1992, pp. 158-168.

[LeMc03] Lehr, W.; McKnight, L.W.: Wireless Internet Access: 3G vs. WiFi? In: Telecommunications Policy, 2003, 27, pp. 351-370. 
[Lind ${ }^{+}$04] Lindner, T.; Fritsch, L.; Plank K.; Rannenberg, K.: Exploitation of Public and Private WiFi Coverage for New Business Models. Forthcoming in: Proceedings of IFIP 2004 - I3E Conference, Toulouse, 2004.

[Loeb96] Loebbecke, C.: Evolution innovativer IT-Infrastrukturen: Dynamische Simulation des deutschen Mobilfunkmarktes. Metzler Poeschel Publishing, Stuttgart, 1996.

[MaPe85] Mahajan, V.; Peterson, R.A.: Models for Innovation Diffusion. Sage Publications, London, 1985.

[NaBr96] Nalebuff, B.J.; Brandenburger, A.M.: Coopetition. Doubleday Books, New York, 1996.

[PeMa78] Peterson, R.A.; Mahajan, V.: Multiproduct Growth Models. In: Sheth, J., ed., Research in Marketing, 1978, Vol. 1, pp. 201-231.

[PiUt97] Pistorius, C.W.I.; Utterback, J.M.: Multi-mode interaction among technologies. In : Research Policy, 1997, Vol. 26, pp. 67-84.

[Pohl96] Pohl, A.: Leapfrogging bei technologischen Innovationen. Gabler: Wiesbaden, 1996.

[Port80] Porter, M.: Competitive Strategy. Free Press: New York, 1980.

[Ratn $\left.{ }^{+} 99\right]$ Ratneshwar, S.; Shocker, A.D.; Cotte, J.: Product, person, and purpose: putting the consumer back into theories of dynamic market behavior. In: Journal of Strategic Marketing, 1999, Vol. 7, pp. 191-208.

[Schi03] Schiller, J.: Mobile Kommunikation. Pearson Studium: Munich, 2003.

[Shoc ${ }^{+}$04] Shocker, A.D.; Bayus, B.L.; Kim, N.: Product Complements and Substitutes in the Real World: The Relevance of "Other Products". In: Journal of Marketing, January 2004, Vol. 68, pp. 28-40.

[TuPo04] Turowski, K.; Pousttchi, K.: Mobile Commerce - Grundlagen und Techniken. Springer: Heidelberg, 2004.

[VeKa03] Venkatesh, R.; Kamakura, W.: Optimal Bundling and Pricing under Monopoly: Contrasting Complements and Substitutes from Independently Valued Products. In: Journal of Business, 2003, Vol. 76, No. 2, pp. 211-231.

[Yada94] Yadav, M.: How Buyers Evaluate Product Bundles: A Model of Anchoring and Adjustment. In: Journal of Consumer Research, 1994, Vol. 21, pp. 342-353. 